\title{
Commentary \\ Macrophage migration inhibitory factor, infection, the brain, and corticosteroids
}

\author{
Madelijn Geldhoff, Barry B Mook-Kanamori and Diederik van de Beek
}

Department of Neurology, Center of Infection and Immunity Amsterdam (CINIMA), Academic Medical Center, University of Amsterdam, PO Box 22660, 1100DD Amsterdam, The Netherlands

Corresponding author: Diederik van de Beek, d.vandebeek@amc.uva.nl

Published: 27 July 2009

Critical Care 2009, 13:170 (doi:10.1186/cc7970)

This article is online at http://ccforum.com/content/13/4/170

(c) 2009 BioMed Central Ltd

See related research by Ostergaard and Benfield, http://ccforum.com/content/13/3/R101

\begin{abstract}
Bacterial meningitis is a complex disorder in which injury is caused, in part, by the causative organism and, in part, by the host's own inflammatory response. Macrophage migration inhibitory factor (MIF) is a pro-inflammatory cytokine and a neuro-endocrine mediator that might play a role in pneumococcal meningitis. Here, we discuss the role of MIF in infection, the brain, and corticosteroids and conclude that experimental meningitis studies have to determine whether MIF is a potential target for adjunctive therapy in pneumococcal meningitis.
\end{abstract}

In the previous issue of Critical Care, Ostergaard and Benfield [1] described cerebrospinal fluid macrophage migration inhibitory factor (MIF) levels in 171 patients with clinically suspected meningitis at time of admission. Elevated MIF levels were observed in patients with purulent meningitis with known bacterial aetiology versus patients with viral infection, no known aetiology, or no meningitis. Cerebrospinal fluid MIF levels had limited predictive value in distinguishing between life-threatening bacterial meningitis and other aetiologies when evaluating a patient suspected of having meningitis and therefore cannot be used for diagnostic purposes. This study did, however, present several interesting findings: among the patients with purulent meningitis, elevated cerebrospinal fluid MIF levels were associated with increased need for assisted ventilation and with impaired consciousness. Furthermore, patients with pneumococcal meningitis in particular had elevated cerebrospinal fluid MIF levels.

MIF is a multi-functional protein that acts both as a cytokine [2] and a neuro-endocrine mediator [3]. It is abundantly expressed in various cell types, including cells of the immune system, cells of the central nervous system, epithelial cells (of the skin, kidney, and liver), pancreatic beta cells, cardiac myocytes, endothelial cells, and fibroblasts [4]. MIF has been reported to play a role in the pathogenesis of several inflam- matory and infectious diseases, including sepsis and septic shock [5].

As a pro-inflammatory cytokine, MIF is produced in response to endotoxin, exotoxins, Gram-positive and Gram-negative bacteria, mycobacteria, malaria pigment, and the proinflammatory cytokines tumour necrosis factor-alpha (TNF- $\alpha$ ) and interferon-gamma [4,6]. In macrophages, MIF acts in an autocrine fashion, leading to the production of proinflammatory cytokines interleukin-8 (IL-8), IL-1 $\beta$, TNF- $\alpha$, and nitric oxide [7]. In addition, MIF enhances Toll-like receptor-4 expression on the macrophage surface, increases phagocytosis and intracellular killing, and inhibits apoptosis [6]. Furthermore, MIF stimulates T-lymphocyte activation and B-lymphocyte antibody production [5].

As a neuro-endocrine mediator, MIF is secreted by anterior pituitary cells in response to low serum glucocorticoids levels, thereby overriding the inhibitory effect of glucocorticoids on the immune response [3]. MIF selectively limits corticosteroidmediated immune depression without influencing other physiological effects of glucocorticoids during the stress response. However, at high glucocorticoid levels, MIF is no longer able to effectively limit corticosteroid-mediated pathways, thereby preventing an excessive and potentially harmful immune response [5].

Bacterial meningitis occurs in between 2.6 and 6 persons per 100,000 per year in developed countries and may be up to 10 times more prevalent in some areas of developing countries [8]. Vaccination strategies have substantially changed the epidemiology of bacterial meningitis during the past two decades [9]. Today, bacterial meningitis strikes more adults than children and the most common causative pathogen is Streptococcus pneumoniae. Despite advances in medical

$\mathrm{IL}=$ interleukin; MIF = macrophage migration inhibitory factor; TNF- $\alpha=$ tumour necrosis factor-alpha. 
care, the mortality due to pneumococcal meningitis ranges from $16 \%$ to $37 \%$ and neurological sequelae are estimated to occur in $30 \%$ to $52 \%$ of surviving adults [10].

Central nervous system inflammation of any kind is poorly tolerated. Experimental meningitis models have shown that inflammatory responses within the enclosed spaces of the brain and spinal cord lead to destructive secondary effects [11]. Pharmacological attempts to modulate this inflammatory response may be essential for the development of new therapeutic strategies in the treatment of this life-threatening disease. Currently, dexamethasone is the only accepted, and clinically proven, adjunctive therapy for the treatment of patients with bacterial meningitis [12,13]. The exact working mechanism by which dexamethasone prevents deaths in bacterial meningitis remains unknown [14]. Despite these encouraging results of adjunctive dexamethasone, the high mortality rate among patients with meningitis stresses the need for new adjunctive treatment strategies.

In patients with sepsis, elevated MIF levels were associated with increased mortality [15]. Corticosteroid therapy has been used in varied doses for sepsis and related syndromes without any clear reduction of mortality. However, since 1998, sepsis studies have consistently used prolonged low-dose corticosteroid therapy, and analysis of this subgroup suggests a beneficial drug effect on short-term outcome [16]. Patients with septic shock who are treated with high-dose corticosteroids have lower serum MIF levels compared to those not treated with high-dose corticosteroids [15]. In a mouse model of endotoxin- or bacterial peritonitis-induced septic shock, neutralizing antibodies to MIF increased survival $[2,6]$.

In conclusion, MIF appears to play a role in central nervous system infections and has an interaction with therapeutic corticosteroids. Therefore, MIF regulation may be involved in the mechanism by which early dexamethasone treatment of bacterial meningitis in adults improves outcome. Studies in animal models of pneumococcal meningitis will have to determine whether MIF is a potential target for adjunctive therapy in the future.

\section{Competing interests}

The authors declare that they have no competing interests.

\section{References}

1. Ostergaard $\mathrm{C}$, Benfield $\mathrm{T}$ : Macrophage migration inhibitory factor in cerebrospinal fluid from patients with central nervous system infection. Crit Care 2009, 13:R101.

2. Bernhagen J, Calandra T, Mitchell RA, Martin SB, Tracey KJ, Voelter W, Manogue KR, Cerami A, Bucala R: MIF is a pituitaryderived cytokine that potentiates lethal endotoxaemia. Nature 1993, 365:756-759.

3. Calandra T, Bernhagen J, Metz CN, Spiegel LA, Bacher M, Donnelly T, Cerami A, Bucala R: MIF as a glucocorticoid-induced modulator of cytokine production. Nature 1995, 377:68-71.

4. Bacher M, Meinhardt A, Lan HY, Mu W, Metz CN, Chesney JA, Calandra T, Gemsa D, Donnelly T, Atkins RC, Bucala R: Migration inhibitory factor expression in experimentally induced endotoxemia. Am J Pathol 1997, 150:235-246.
5. Flaster $\mathrm{H}$, Bernhagen J, Calandra T, Bucala R: The macrophage migration inhibitory factor-glucocorticoid dyad: regulation of inflammation and immunity. Mol Endocrinol 2007, 21:12671280.

6. Calandra T: Macrophage migration inhibitory factor and host innate immune responses to microbes. Scand J Infect Dis 2003, 35:573-576.

7. Bozza M, Satoskar AR, Lin G, Lu B, Humbles AA, Gerard C, David JR: Targeted disruption of migration inhibitory factor gene reveals its critical role in sepsis. J Exp Med 1999, 189:341346.

8. van de Beek D, de Gans J, Tunkel AR, Wijdicks EF: Communityacquired bacterial meningitis in adults. N Engl J Med 2006, 354:44-53.

9. van de Beek D, de Gans J, Spanjaard L, Weisfelt M, Reitsma JB, Vermeulen $\mathrm{M}$ : Clinical features and prognostic factors in adults with bacterial meningitis. N Engl J Med 2004, 351:1849-1859.

10. Weisfelt M, van de Beek D, Spanjaard L, Reitsma JB, de Gans J: Clinical features, complications, and outcome in adults with pneumococcal meningitis: a prospective case series. Lancet Neurol 2006, 5:123-129.

11. Fitch MT, van de Beek D: Drug Insight: steroids in CNS infectious diseases-new indications for an old therapy. Nat Clin Pract Neurol 2008, 4:97-104.

12. de Gans J, van de Beek D: Dexamethasone in adults with bacterial meningitis. N Engl J Med 2002, 347:1549-1556.

13. van de Beek D, de Gans J, McIntyre P, Prasad K: Corticosteroids for acute bacterial meningitis. Cochrane Database Syst Rev 2007, 1:CD004405.

14. van de Beek D: Brain teasing effect of dexamethasone. Lancet Neurol 2007, 6:203-204.

15. Emonts M, Sweep FC, Grebenchtchikov N, Geurts-Moespot A, Knaup M, Chanson AL, Erard V, Renner P, Hermans PW, Hazelzet $\mathrm{JA}$, Calandra $\mathrm{T}$ : Association between high levels of blood macrophage migration inhibitory factor, inappropriate adrenal response, and early death in patients with severe sepsis. Clin Infect Dis 2007, 44:1321-1328.

16. Annane D, Bellissant E, Bollaert PE, Briegel J, Confalonieri M, De GR, Keh D, Kupfer Y, Oppert M, Meduri GU: Corticosteroids in the treatment of severe sepsis and septic shock in adults: a systematic review. JAMA 2009, 301:2362-2375. 